\title{
Validação de metodologia para doseamento e estudo de equivalência farmacêutica de comprimidos de lamivudina $150 \mathrm{mg}$
}

\author{
Christian Fernandes*, Ligia Maria Moreira de Campos, Gérson Antônio Pianetti
}

Departamento de Produtos Farmacêuticos, Faculdade de Farmácia, Universidade Federal de Minas Gerais

*Correspondência:

C. Fernandes

Departamento de Produtos

Farmacêuticos - Faculdade de

Farmácia - UFMG

Av. Olegário Maciel, 2360 - sala 511 -

Lourdes

30180-112 Belo Horizonte - MG -

Brasil

E-mail: cfernandes@iqsc.usp.br
A lamivudina é um fármaco indicado para o tratamento de infecção por HIV, tipos 1 e 2. Tem sido extensivamente utilizada no Brasil, em programa público do Ministério da Saúde. Visando à verificação da qualidade dos medicamentos contendo este fármaco foi estabelecida e validada metodologia para determinação do teor da lamivudina. Foi também realizado estudo de equivalência farmacêutica frente ao medicamento referência. Parâmetros físicos e físico-químicos de comprimidos de liberação imediata de diferentes lotes de quatro laboratórios ( $G, A, B$ e $C$ ) foram avaliados. O método proposto para o doseamento, por cromatografia líquida de alta eficiência, mostrou precisão, exatidão, linearidade e especificidade. Os lotes dos laboratórios $G$, $A$ e $B$ apresentaram resultados adequados em todos os testes aos quais foram submetidos. O produto $G$ (referência) mostrou similaridade entre seus lotes com dissolução rápida. Os produtos A e B mostraram diferenças entre seus lotes, mas ao final do tempo determinado alcançaram cedência semelhante ao do produto $G$, sendo considerados equivalentes farmacêuticos ao medicamento referência. Os lotes do produto $C$ não foram similares entre si e apresentaram baixa dissolução, não possuindo qualidade adequada para o consumo humano.

\section{INTRODUÇÃO}

A lamivudina (também denominada 3TC) é o enantiômero cis(-) da 2'-desoxi-3'-tiacitidina (Figura 1), pertencendo à classe dos análogos nucleosídeos utilizados no tratamento de infecção por HIV, tipos 1 e 2 (Somadossi et al., 1992). Apresenta boa atividade inibitória contra HIV em linfócitos sanguíneos periféricos, monócitos, macrófagos e várias células tumorais. Além disso, possui ação sinérgica quando combinado com outros fármacos,

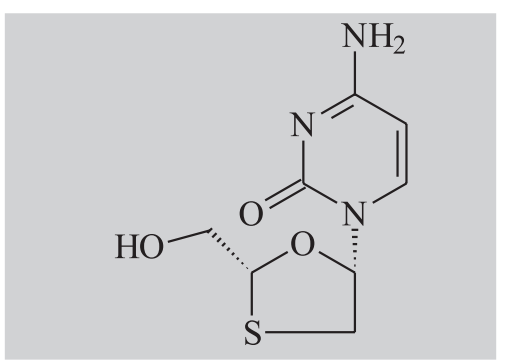

FIGURA 1 - Estrutura da lamivudina.

Fonte: Plumb et al., 1996
Unitermos

- Lamivudina

- Equivalência farmacêutica

- Validação 
entre os quais, zidovudina, didanosina, estavudina e saquinavir (Perry, Faulds, 1997).

A lamivudina atua por meio da inibição da enzima transcriptase reversa, responsável pela conversão do RNA viral em uma cópia bifilamentar de DNA. Após se ligar a esta enzima, a lamivudina gera a interrupção do alongamento da cadeia de DNA viral (Hayden, 1996).

A lamivudina apresenta-se como pó cristalino branco a branco-amarelado e possui massa molecular de 229,26 g/mol (Kyoko et al., 1997). Pode ser obtida sob a forma de cristais aciculares ou bipiramidais, sendo esta última preferida na produção de formas farmacêuticas sólidas, devido às melhores características de fluidez (Glaxo, 1992).

No Brasil, este fármaco tem sido extensivamente utilizado no tratamento de pacientes portadores da Síndrome da Imunodeficiência Adquirida (SIDA) em programa público do Ministério da Saúde, mundialmente conhecido.

O governo brasileiro tem conseguido importantes vitórias no âmbito da produção de medicamentos. O custo dos programas especiais de saúde tem sido reduzido com a diminuição dos custos dos medicamentos, devido principalmente à sua produção por laboratórios oficiais.

Entretanto, os laboratórios brasileiros carecem de especificações farmacopéicas para diversos fármacos, a lamivudina entre eles, para que a qualidade requerida quando da produção dos medicamentos atenda às necessidades brasileiras.

Dentro da política nacional de saúde está o programa de medicamentos genéricos, garantido pelas resoluções aprovadas, sendo a mais recente em 19 de março de 2002 - RDC no 84 (Brasil, 2002).

A intercambialidade do medicamento é aceita após estudos de equivalência farmacêutica e bioequivalência.

Os estudos de equivalência farmacêutica verificam se o medicamento cumpre com os testes farmacopéicos, destacando-se os testes de identificação da substância ativa e dos produtos secundários, verificação do teor do fármaco, da dissolução e do perfil de dissolução (Fernandes, 2001).

O presente trabalho tem por objetivos estabelecer método de doseamento, aplicar metodologia validada para avaliação de lotes de comprimidos de lamivudina e verificar a equivalência farmacêutica.

\section{MATERIAL E MÉTODOS}

\section{Amostras}

Foram utilizados medicamentos de 4 diferentes laboratórios, cujas características estão descritas na Tabela
I. Os medicamentos foram cedidos pelos laboratórios produtores.

\section{Substância Química de Referência}

Foi utilizada lamivudina padrão secundário (lote AWS535A), cedido pela Glaxo Wellcome, com teor declarado de $99,72 \%$.

\section{Reagentes}

Foram utilizados metanol (Merck) - grau HPLC, acetato de amônio (Merck), solução de Karl-Fischer (Merck), ácido acético glacial (Merck) - grau pró-análise.

TABELA I - Características dos lotes dos laboratórios referência, A, B e C

\begin{tabular}{ccc} 
Laboratório & Lote & Validade \\
\hline GLAXO & W1158KA (G1) & $08 / 2000$ \\
WELLCOME & W1509AC (G2) & $01 / 2001$ \\
(Referência) & BO18603 (G3) & $06 / 2002$ \\
\hline A & $00080226(\mathrm{~A} 1)$ & $08 / 2002$ \\
& $00080227(\mathrm{~A} 2)$ & $08 / 2002$ \\
& $00080228(\mathrm{~A} 3)$ & $08 / 2002$ \\
\hline B & $00090878(\mathrm{~B} 1)$ & $09 / 2002$ \\
& $00090879(\mathrm{~B} 2)$ & $09 / 2002$ \\
& $00090880(\mathrm{~B} 3)$ & $09 / 2002$ \\
\hline C & $000808(\mathrm{C} 1)$ & $08 / 2002$ \\
& $000809(\mathrm{C} 2)$ & $08 / 2002$ \\
& $000810(\mathrm{C} 3)$ & $08 / 2002$ \\
\hline
\end{tabular}

\section{Validação do método de doseamento da lamivudina por cromatografia líquida de alta eficiência (CLAE)}

A linearidade foi avaliada pelo método dos mínimos quadrados, com cinco concentrações diferentes $(0,2$ a $0,6 \mathrm{mg} / \mathrm{mL}$ ) e cinco injeções em cada ponto.

A precisão foi determinada realizando-se seis determinações (três injeções cada) a $100 \%$ da concentração teste $(0,4 \mathrm{mg} / \mathrm{mL})$. Foi considerado como limite máximo um valor de desvio padrão relativo (DPR) de 2,0\%.

A especificidade do método foi avaliada por meio da pureza do pico da lamivudina, obtendo-se espectros em cinco pontos do pico.

A exatidão foi determinada após a avaliação da precisão, linearidade e especificidade (International Conference on Harmonization, 2000).

Foram feitas diluições sucessivas para determinação 
do limite de quantificação, considerado como a menor concentração onde o DPR entre as injeções é inferior a 2,0\%.

Posteriores diluições foram realizadas objetivandose a determinação do limite de detecção, que é a menor concentração onde o pico relativo à lamivudina é três vezes superior ao ruído da linha de base.

\section{Determinação de peso}

Foram pesados, individualmente, vinte comprimidos de lamivudina. Calculou-se o peso médio e os desvios individuais em relação a esse valor. Utilizaram-se as especificações descritas na Farmacopéia Brasileira(1988).

\section{Dureza}

Foram submetidas dez unidades ao teste, objetivando verificar a resistência dos mesmos a uma força aplicada diametralmente. A dureza mínima aceitável é 3 kgf (Farmacopéia Brasileira,1988).

\section{Umidade}

A umidade dos comprimidos foi determinada por método volumétrico, utilizando reagente de Karl-Fischer. Foram realizadas duas determinações para cada lote. $\mathrm{O}$ limite máximo permitido é de 3,0\%, segundo especificação do Ministério da Saúde (Brasil, 1999).

\section{Desintegração}

Foi avaliada a capacidade de os comprimidos se desintegrarem em 60 minutos utilizando água mantida a $37^{\circ} \mathrm{C} \pm 1{ }^{\circ} \mathrm{C}$ como líquido de imersão (Farmacopéia Brasileira, 1988).

\section{Doseamento da lamivudina}

O doseamento do fármaco foi feito por meio de cromatografia líquida de alta eficiência, utilizando cromatógrafo HP 1100 com detector de arranjo de diodos (DAD), coluna Merck C-8, $25 \mathrm{~cm}$ de comprimento, 4,6 $\mathrm{mm}$ de diâmetro interno e partículas de $5 \mu \mathrm{m}$. A fase móvel é constituída de (5:95) metanol: solução de acetato de

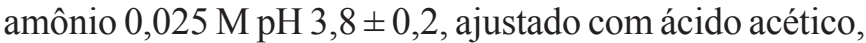
fluxo de $1 \mathrm{~mL} / \mathrm{minuto}$, volume injetado de $10 \mu \mathrm{L}$, detecção no ultravioleta a $270 \mathrm{~nm}$ e temperatura de $30^{\circ} \mathrm{C}$. O padrão e amostras foram preparados na concentração de $0,4 \mathrm{mg} / \mathrm{mL}$, utilizando fase móvel como solvente. A especificação de teor para comprimidos é de $90,0 \%$ a $110,0 \%$ da quantidade declarada.

\section{Uniformidade de conteúdo}

Foram avaliadas, individualmente, dez unidades de cada lote por cromatografia líquida de alta eficiência utilizando as mesmas condições descritas para o doseamento. A quantidade de fármaco presente em cada comprimido deve estar situada entre 85,0 e $115,0 \%$ do valor declarado e o desvio padrão relativo (DPR) deve ser menor ou igual a 6,0\% (Farmacopéia Brasileira,1996).

\section{Identificação}

Foi utilizada a mesma metodologia descrita para o doseamento, sendo comparados os tempos de retenção e perfil dos picos.

\section{Teste de dissolução}

Foi realizado teste de dissolução, utilizando o equipamento Hanson Research Corp. modelo 72RL, nas seguintes condições, determinadas em estudo prévio: água como meio de dissolução, pás como sistema de agitação, velocidade de agitação de $50 \mathrm{rpm}$, tempo de coleta de 30 minutos, tolerância de $80 \%$ e leitura feita no ultravioleta em $270 \mathrm{~nm}$.

\section{Perfil de dissolução}

Seis comprimidos de lamivudina foram avaliados quanto à sua capacidade de liberar o fármaco no meio de dissolução em tempos pré-determinados. As amostras foram coletadas nos tempos 2,$5 ; 5 ; 15 ; 30 ; 45$ e 60 minutos. Foram retirados $10 \mathrm{~mL}$ de amostra, sendo feita a reposição deste volume com o meio de dissolução.

\section{RESULTADOS E DISCUSSÃO}

O método de doseamento por CLAE demonstrou linearidade, apresentando coeficiente de correlação (r) igual a 0,99952 , e a equação da reta: $Y=17,89+$ 12167,8X (Figura 2).

O método também mostrou-se preciso com DPR de $1,45 \%$ (Tabela II).

Os espectros obtidos em cinco pontos do pico no cromatograma da lamivudina (Figura 3) são similares, demonstrando tratar se do mesmo cromóforo.

A exatidão do método foi demonstrada pois os parâmetros precisão, linearidade e especificidade foram previamente estabelecidos.

Foi considerado como limite de quantificação a concentração de $0,75 \mathrm{mg} / \mathrm{mL}$, pois essa foi a mais baixa concentração onde o DPR era inferior a 2,0\% (Tabela III). 
A concentração da solução que apresentou pico relativo à lamivudina três vezes superior ao ruído da linha de base foi de $0,025 \mathrm{mg} / \mathrm{mL}$. O cromatograma demonstrando o pico da lamivudina nessas condições está apresentado na Figura 4.

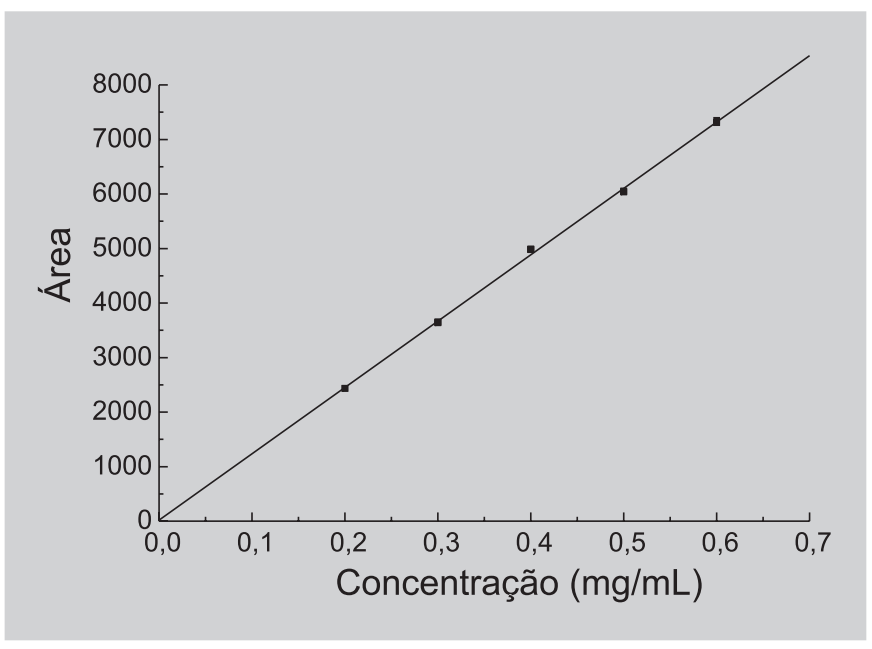

FIGURA 2 - Representação gráfica da curva padrão da lamivudina obtida por CLAE.
Os resultados encontrados para o teste de determinação de peso estão apresentados na Tabela IV. Apenas o lote $\mathrm{A} 3$ apresentou quatro unidades com desvio, em relação ao peso médio, superior ao tolerado. Todos os outros lotes estavam adequados.

Os resultados encontrados para os testes de dureza, umidade, doseamento e uniformidade de conteúdo estão apresentados na Tabela V.

A dureza estava adequada em todos os lotes analisados, indicando boa resistência dos comprimidos durante os processos de embalagem, armazenamento e transporte.

Os lotes G3, A2 e C1 apresentaram teor de umidade superior ao máximo permitido. O teor de umidade deve ser avaliado, pois pode contribuir para a degradação do fármaco.

Todos os lotes submetidos ao teste de desintegração estavam adequados, ou seja, estavam completamente desintegrados ao final de 60 minutos.

O teor de lamivudina nos comprimidos estava dentro da faixa especificada em todos os lotes, com valores próximos de $100 \%$.

No teste de uniformidade de conteúdo, o teor de

TABELA II - Valores de área utilizados no cálculo da precisão

\begin{tabular}{lcccccc}
\hline Dias & $\mathbf{1}$ & $\mathbf{2}$ & $\mathbf{3}$ & $\mathbf{4}$ & $\mathbf{5}$ & $\mathbf{6}$ \\
\hline & 4990,9 & 5100,0 & 5186,5 & 5179,3 & 5160,2 & 5063,7 \\
& 4984,0 & 5065,7 & 5173,4 & 5166,3 & 5214,2 & 5013,9 \\
& 4980,1 & 5078,0 & 5130,1 & 5123,0 & 5137,8 & 5114,4 \\
\hline Média & \multicolumn{7}{c}{5} \\
\hline DPR & & 5103,4 & & \\
\hline
\end{tabular}
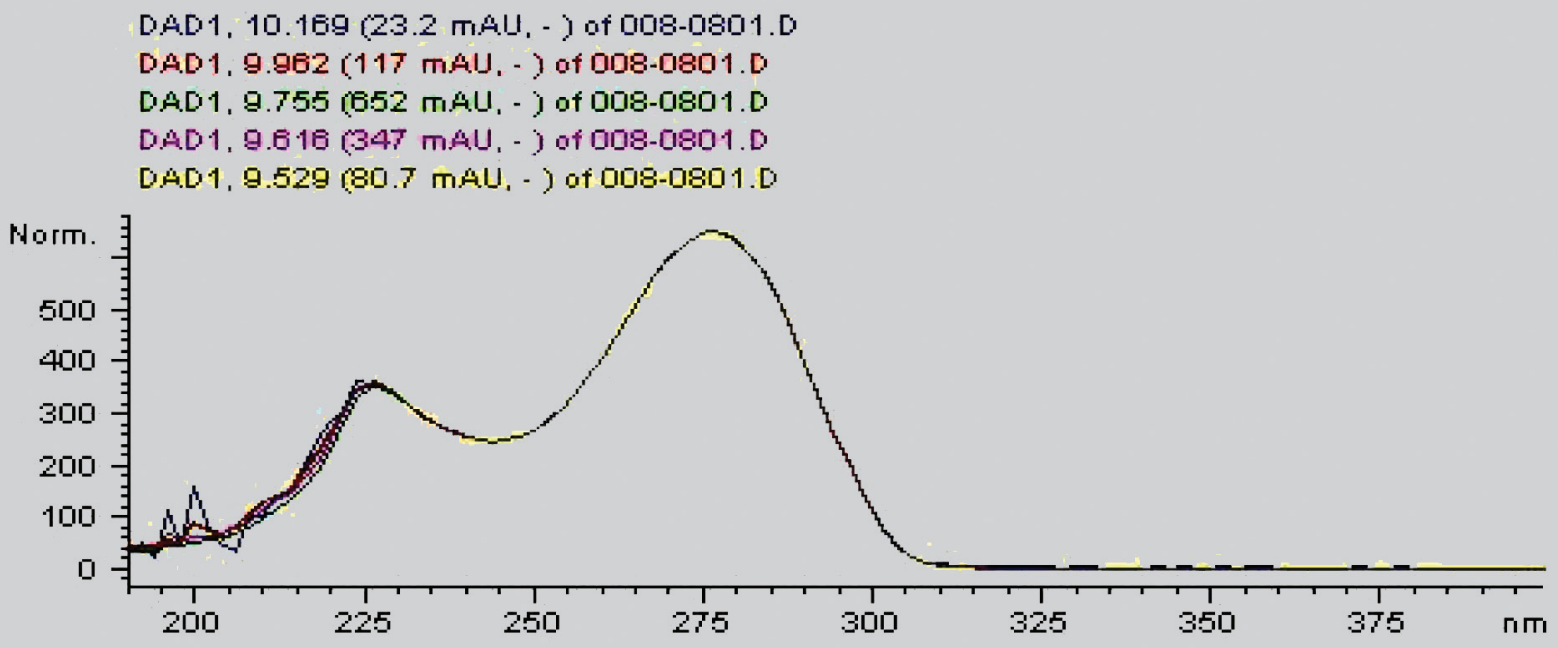

FIGURA 3 - Espectros da lamivudina obtidos em cinco pontos diferentes do pico. 
TABELA III - Valores de área utilizados na determinação do limite de quantificação da lamivudina

\begin{tabular}{lccccccccc}
\hline Concentração (mg/mL) & $\mathbf{1 0 0}$ & $\mathbf{5 0}$ & $\mathbf{2 5}$ & $\mathbf{1 2 , 5}$ & $\mathbf{6 , 2 5}$ & $\mathbf{3 , 0}$ & $\mathbf{1 , 5}$ & $\mathbf{0 , 7 5}$ & $\mathbf{0 , 4}$ \\
\hline Áreas & 1241,9 & 612,7 & 312,2 & 158,1 & 83,0 & 39,3 & 19,3 & 9,7 & 5,3 \\
& 1238,9 & 612,1 & 312,2 & 158,1 & 81,7 & 39,1 & 18,8 & 9,9 & 5,1 \\
& 1239,6 & 611,6 & 312,5 & 159,0 & 80,8 & 38,5 & 19,6 & 10,1 & 6,1 \\
& 1239,9 & 611,9 & 312,2 & 157,1 & 81,2 & 38,7 & 19,3 & 10,0 & 5,7 \\
\hline Média das áreas & 1239,1 & 612,1 & 311,9 & 157,1 & 81,2 & 39,0 & 19,3 & - & - \\
\hline DPR (\%) & 1239,9 & 612,1 & 312,2 & 157,9 & 81,58 & 38,9 & 19,3 & 9,9 & 5,6 \\
\hline
\end{tabular}

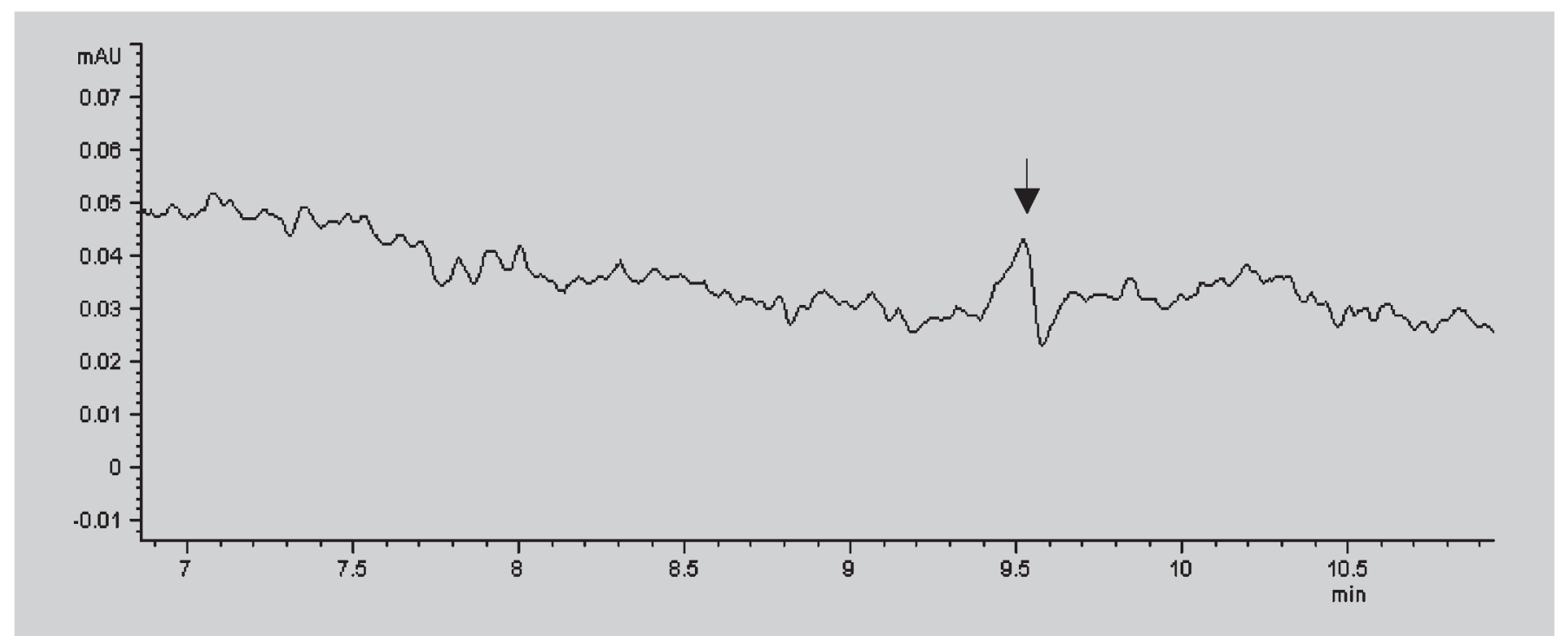

FIGURA 4 - Cromatograma da solução padrão a $0,025 \mathrm{mg} / \mathrm{mL}$ onde se observa pico relativo à lamivudina no tempo de retenção de cerca de 9,5 minutos.

TABELA IV - Valores obtidos no teste de determinação de peso

\begin{tabular}{llll}
\hline Lotes & Peso médio $(\mathbf{m g})$ & \% de desvio & $\begin{array}{l}\text { Resultado } \\
\text { (em unidades fora da faixa especificada) }\end{array}$ \\
\hline G1 & 312,17 & $-1,3$ a 1,7 & Nenhuma \\
G2 & 311,98 & $-4,0$ a 3,4 & Nenhuma \\
G3 & 312,57 & $-2,2$ a 2,8 & Nenhuma \\
A1 & 302,97 & $-2,1$ a 2,7 & Nenhuma \\
A2 & 302,16 & $-7,4$ a 5,9 & Duas \\
A3 & 304,56 & $-6,1$ a 9,4 & Quatro \\
B1 & 292,94 & $-4,6$ a 4,4 & Nenhuma \\
B2 & 293,24 & $-5,1$ a 2,6 & Uma \\
B3 & 290,91 & $-2,9$ a 2,9 & Nenhuma \\
C1 & 294,12 & $-2,9$ a 3,0 & Nenhuma \\
C2 & 307,15 & $-2,1$ a 3,4 & Nenhuma \\
C3 & 313,98 & $-6,0$ a 2,6 & Uma \\
\hline
\end{tabular}


TABELA V - Valores obtidos nos testes de dureza, umidade, doseamento e uniformidade de conteúdo (obtidos por CLAE)

\begin{tabular}{lcccc}
\hline Lote & $\begin{array}{c}\text { Dureza média (kgf) } \\
\mathbf{n = 1 0}\end{array}$ & $\begin{array}{c}\text { Umidade média (\%) } \\
\mathbf{n = 3}\end{array}$ & $\begin{array}{c}\text { Teor médio (\%) } \\
\mathbf{n = 3}\end{array}$ & $\begin{array}{c}\text { Uniformidade de conteúdo } \\
\text { (média) e DPR }\end{array}$ \\
\hline G1 & 9,4 & 2,90 & 100,75 & $97,82 / 1,53$ \\
G2 & 8,8 & 2,84 & 101,23 & $98,42 / 3,69$ \\
G3 & 3,9 & 9,04 & 97,85 & $96,89 / 3,36$ \\
A1 & 9,6 & 2,87 & 101,53 & $102,42 / 2,23$ \\
A2 & 9,3 & 4,08 & 100,81 & $97,70 / 2,15$ \\
A3 & 8,6 & 2,63 & 100,81 & $97,86 / 3,14$ \\
B1 & 8,6 & 2,54 & 99,26 & $92,93 / 2,88$ \\
B2 & 8,4 & 2,48 & 98,57 & $93,13 / 1,59$ \\
B3 & 8,8 & 2,43 & 99,48 & $101,02 / 4,74$ \\
C1 & 4,2 & 3,31 & 99,90 & $92,42 / 3,34$ \\
C2 & 3,8 & 2,57 & 99,89 & $94,78 / 3,68$ \\
C3 & 3,6 & 2,77 & 101,29 & $98,47 / 2,73$ \\
\hline
\end{tabular}

lamivudina estava entre $85,0 \%$ e $115,0 \%$ em todas as unidades testadas, em todos os lotes e o desvio padrão relativo foi inferior a $6,0 \%$.

Os cromatogramas obtidos por CLAE para lamivudina padrão secundário e comprimidos estão apresentados nas Figuras 5 e 6.

Os cromatogramas da lamivudina padrão secundário e comprimidos possuem o mesmo perfil e tempos de retenção próximos: 9,431 minutos para o padrão secundário e 9,318 minutos para o comprimido. O cromatograma mostrado, referente ao comprimido, representa o compor- tamento de todos os outros lotes de comprimidos analisados.

Os resultados obtidos no teste de dissolução estão apresentados na Tabela VI.

Existe diferença importante entre os conceitos de controle de qualidade de um medicamento e os estudos a serem realizados com dois medicamentos de laboratórios diferentes com a finalidade de se determinar equivalência entre lotes. No primeiro caso, o medicamento deve cumprir com os requisitos farmacopéicos para ter definida a sua qualidade. Neste caso, o teste de dissolução realizado

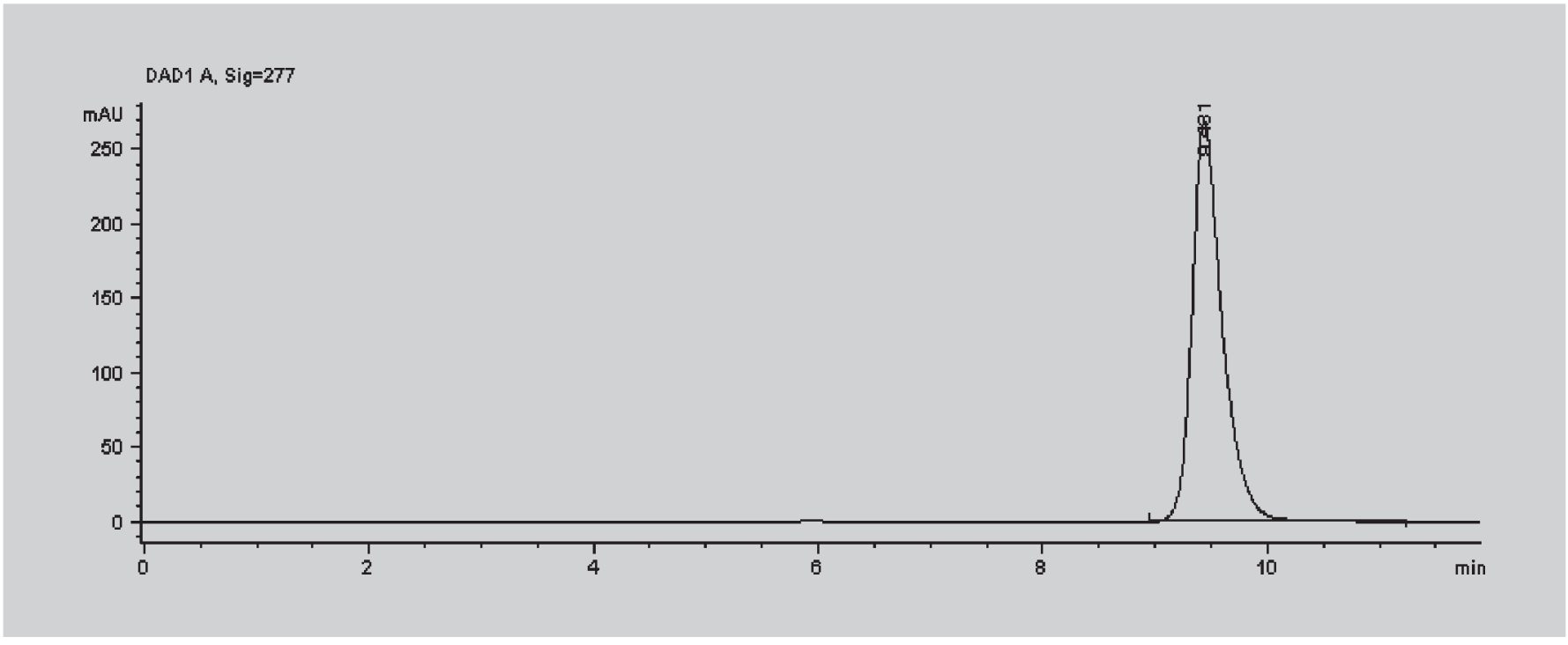

FIGURA 5 - Cromatograma da lamivudina padrão secundário a $0,4 \mathrm{mg} / \mathrm{mL}$ obtido por CLAE. Coluna C-8 $25 \mathrm{~cm} \mathrm{x}$

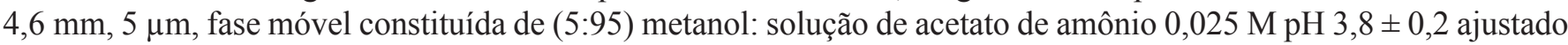
com ácido acético. 


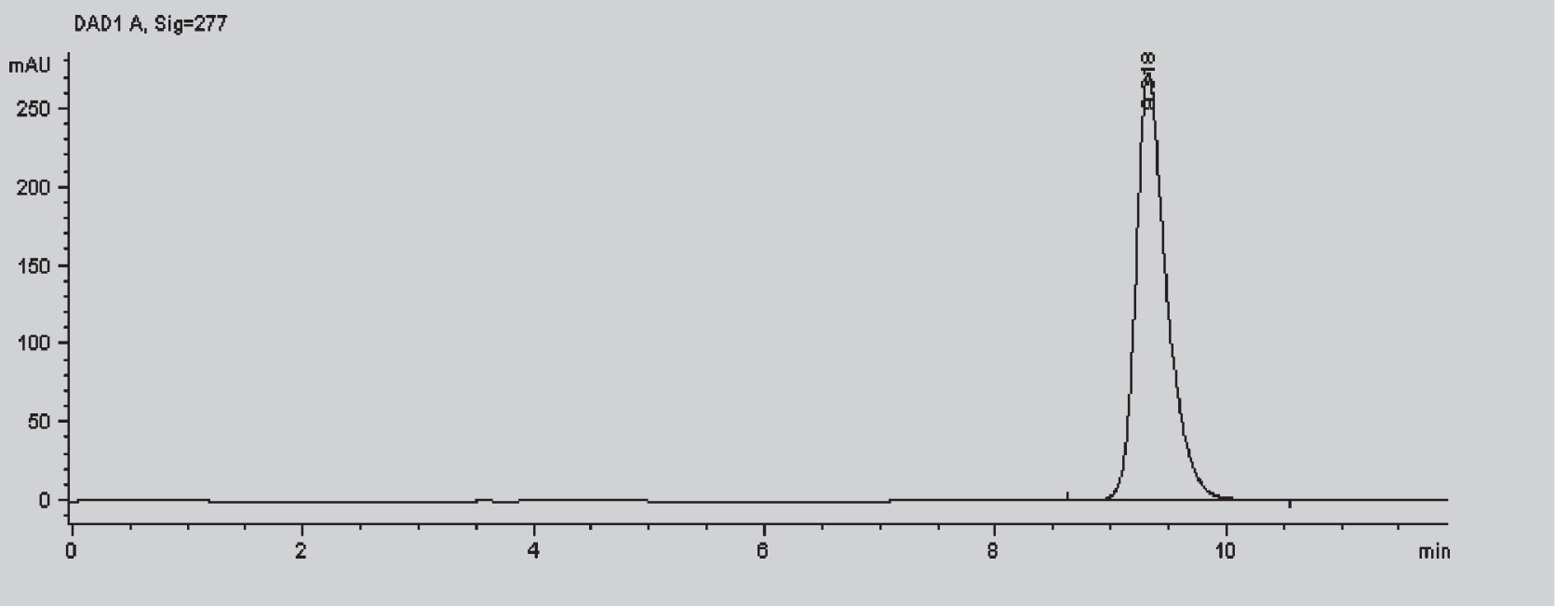

FIGURA 6 - Cromatograma da lamivudina comprimidos a $0,4 \mathrm{mg} / \mathrm{mL}$ obtido por CLAE. Coluna C-8 $25 \mathrm{~cm}$ x 4,6 mm,

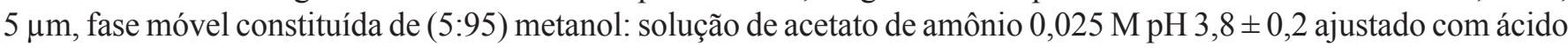
acético.

TABELA VI - Valores de porcentagem de cedência obtidos no teste de dissolução de comprimidos de lamivudina determinados por espectrofotometria de absorção no ultravioleta

\begin{tabular}{lcccccccccccc}
\hline Lote & G1 & G2 & G3 & A1 & A2 & A3 & B1 & B2 & B3 & C1 & C2 & C3 \\
\hline \% Cedência & 97,9 & 101,8 & 99,4 & 103,6 & 100,3 & 100,6 & 98,8 & 100,7 & 101,2 & 73,9 & 7,2 & 11,7 \\
\hline
\end{tabular}

com um único ponto já é suficiente para avaliar a qualidade do medicamento. No segundo caso, além de cumprir com os requisitos farmacopéicos, o medicamento deve apresentar comportamento semelhante ao medicamento referência. Nesta situação, o perfil de dissolução trará importante informação para avaliação da similaridade.

Os comprimidos de lamivudina são de liberação imediata, ou seja, devem apresentar alta porcentagem de dissolução em poucos minutos. No entanto, isto não ocorreu para todos os lotes.

Os lotes do medicamento referência $(\mathrm{G})$ são bastante similares entre si apresentando cedência de cerca de 96\% em 5 minutos (Figura 7).

Para os lotes A1, A2 e A3 (Figura 8) os perfis são um pouco mais diferenciados, com dissolução um pouco mais lenta em relação ao produto G. No entanto, ao final do teste a quantidade dissolvida foi similar.

No caso dos lotes B1, B2 e B3 os perfis também se mostraram pouco similares. No entanto, cerca de $100 \%$ de dissolução foi alcançada em 15 minutos (Figura 9).

Para o laboratório C (Figura 10), apenas um dos lotes apresentou cedência adequada ao final de 60 minutos
$(\mathrm{C} 1=98,8 \%)$. Os outros dois lotes apresentaram baixa porcentagem de cedência. Os perfis são muito diferentes, indicando haver problemas relacionados aos adjuvantes utilizados, bem como ao processo de produção desses comprimidos.

Além disso, os valores de porcentagem de cedência obtidos para os lotes C1, C2 e C3 (73,9\%; 7,2\% e 11,7\%, respectivamente) no teste de dissolução (tempo de 30 minutos) apresentam grande diferença daqueles obtidos no teste de perfil de dissolução $(52,79 \% ; 17,07 \%$ e $17,30 \%)$. Apesar de ficar claro que o lote $\mathrm{C} 1$ apresenta capacidade de dissolução superior aos outros dois lotes, nota-se baixa homogeneidade dentro dos lotes, percebida nas diferenças de resultados nos testes de dissolução e perfil de dissolução. Isso não ocorre para os lotes dos laboratórios $\mathrm{G}, \mathrm{A}$ e $\mathrm{B}$, nos quais os valores são bem próximos.

A avaliação da dissolução de formulações sólidas apresenta-se atualmente como etapa fundamental para a produção de medicamentos de qualidade. Conseqüentemente, os laboratórios produtores devem realizar estudos prévios buscando desenvolver comprimidos que atendam aos requisitos de cedência. 


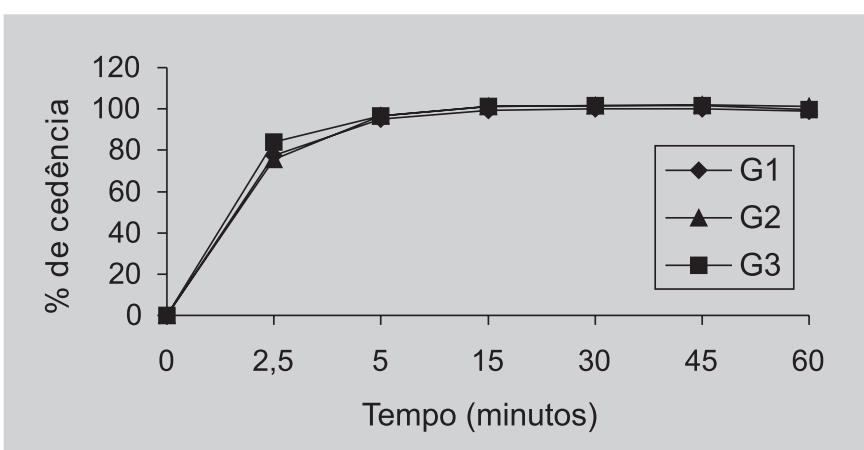

FIGURA 7 - Perfis de dissolução dos lotes G1, G2 e G3 obtidos por espectrofotometria de absorção no ultravioleta.

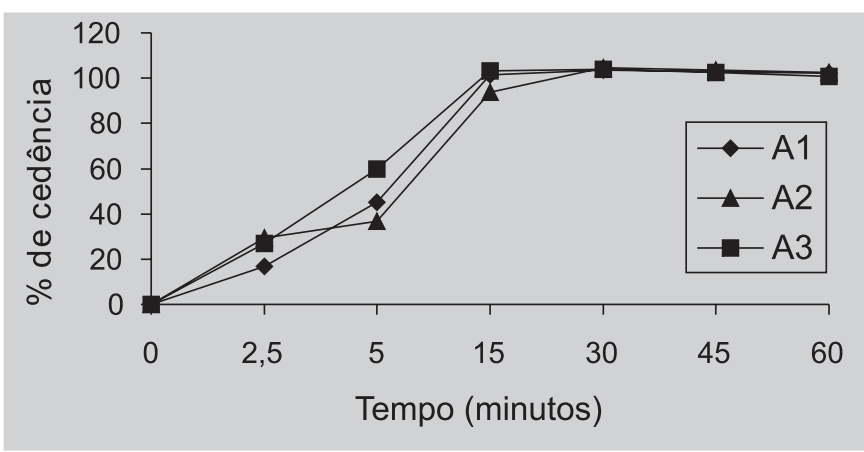

FIGURA 8 - Perfis de dissolução dos lotes A1, A2 e A3 obtidos por espectrofotometria de absorção no ultravioleta.

\section{CONCLUSÕES}

O método proposto para doseamento de comprimidos de lamivudina por CLAE foi validado, mostrando especificidade, linearidade, precisão e exatidão.

Os lotes dos laboratórios G, A e B apresentaram resultados adequados nos testes aos quais foram submetidos. Os lotes dos laboratórios A e B mostraram-se equivalentes farmacêuticos ao medicamento referência G. Apesar do comportamento inicial do perfil de dissolução ser diferente do medicamento referência, isto não compromete a validade do resultado apresentado. Quanto aos lotes do laboratório $\mathrm{C}$, o perfil de dissolução dos mesmos evidencia que o produto não tem qualidade para o consumo humano, não podendo ser dispensado, nem submetido ao estudo de bioequivalência nestas condições.

Os resultados obtidos no teste de perfil de dissolução servem de parâmetro importante para o desenvolvimento da forma farmacêutica, pois demonstram claramente que a diferença de quantidade de fármaco liberado em meio aquoso poderá comprometer o resultado do teste de bioequivalência em um primeiro momento bem como o tratamento do paciente.

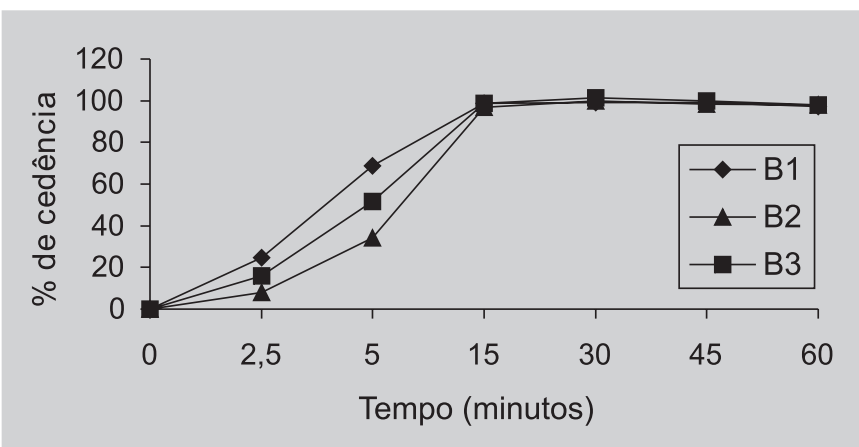

FIGURA 9 - Perfis de dissolução dos lotes B1, B2 e B3 obtidos por espectrofotometria de absorção no ultravioleta.

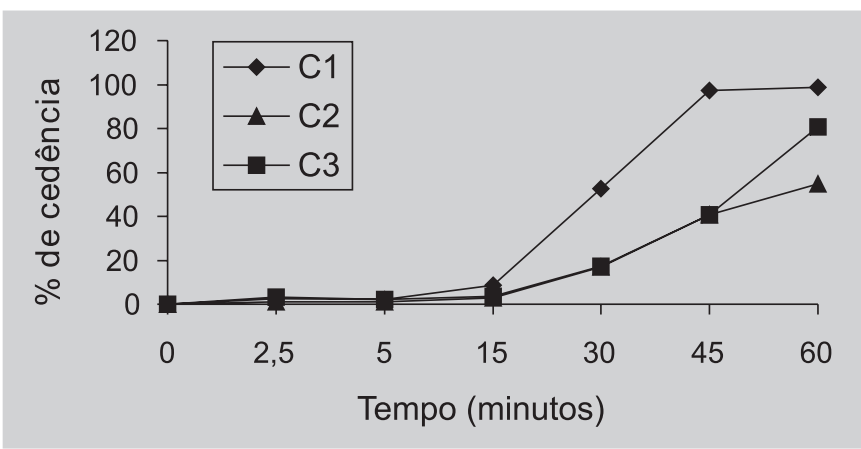

FIGURA 10 - Perfis de dissolução dos lotes C1, C2 e C3 obtidos por espectrofotometria de absorção no ultravioleta.

\section{ABSTRACT \\ Methodology validation for assay and pharmaceutical equivalency study for lamivudine tablets $150 \mathrm{mg}$}

Lamivudine is a drug used in the treatment of types 1 and 2 HIV infections. It has been widely used in Brazil, in public programs of the Health Ministry. This work reports lamivudine assay methodologies, which have been developed and validated. Pharmaceutical equivalency studies were also performed for lamivudine tablets. Physical and physicochemical parameters of immediate release reference and test tablets of four different laboratories ( $G, A, B$ and $C$ ) were evaluated. The proposed analytical method, high performance liquid chromatography, presented satisfactory precision, accuracy, linearity and specificity. Batches from laboratories $G, A$ and $B$ showed appropriate results in all tests to which they were submitted. Tablet batches from laboratory $G$ (reference) showed similar dissolution profile and fast dissolution rate. The products $A$ and $B$ showed differences between their batches, in regards to 
the dissolution rates at the initial profile. However at the end of the profile they reached similar release to the reference, product $G$. Therefore they can be considered pharmaceutical equivalents to the reference product. Batches of product from laboratory C showed much more differences with reduced dissolution presenting no appropriate quality for human consumption.

UNITERMS: Lamivudine. Pharmaceutical equivalency. Validation

\section{REFERÊNCIAS BIBLIOGRÁFICAS}

BRASIL. Ministério da Saúde. Ficha técnica de análise de comprimidos de lamivudina $150 \mathrm{mg}$, programa DST/ AIDS, 1999. [Separata].

BRASIL. Ministério da Saúde. Resolução RDC n. 84, de 19 de março de 2002. Aprova o regulamento técnico para medicamentos genéricos. Diário Oficial da União, Brasília, 20 mar. 2002, seção 1, p. 75.

FARMACOPÉIA brasileira. 4. ed. São Paulo: Atheneu, 1988. Parte1, cap. V.

FARMACOPÉIA brasileira. 4.ed. SãoPaulo: Atheneu, 1996. Parte 2, cap. V.1.6.

FERNANDES, C. Estudo de equivalência farmacêutica de comprimidos de lamivudina $150 \mathrm{mg}$. Belo Horizonte, 2001. 203p. [Dissertação de mestrado. Faculdade de Farmácia da Universidade Federal de Minas Gerais]

GLAXO GROUP RESEARCH LIMITED, GreenfordMiddlesex, Paul Ravenscroft; Tony Gordon Roberts; Paul Evans. Crystalline oxthiolane derivatives. Int. $\mathrm{Cl}$. C07D411/04, A61K31/505. GB n. 9111902, EP 0517145A1, 92109221.9 .03 jun. 1991; 02 jun. 1992. European Patent Application: Bulletin 92/50, 09 dez. 1992.
HAYDEN, F.G. Fármacos antivirais. In: GILMAN, A. G.; RALL, T. W.; NIES, A. S.; TAYLOS, P., eds. GOODMAN \& GILMAN As bases farmacológicas da terapêutica. 9. ed. Rio de Janeiro: MacGraw Hill, 1996. Cap. 50, p. 876-896.

INTERNATIONAL CONFERENCE ON HARMONISATION. Validation of analytical procedures: methodology. Disponível em: <http://www.ich.org>. Acesso em: 20 out. 2000.

KYOKO, H.; ETSUKO, U.; MASUMITSU, T. Physicochemical properties and stability of Epivir tablets. Kagaku Ryoho no Ryoiki, Osaka, v. 13, p. 1170-1172, 1997.

PERRY, C.M.; FAULDS, D. Lamivudine: a review of its antiviral activity, pharmacokinetic properties and therapeutic efficacy in the management of HIV infection. Drugs, Auckland, v.53, p. 657-680, 1997.

PLUMB, R.S.; GRAY, R.D.M.; HARKER, A.J.; TAYLOR, $\mathrm{S}$. High-performance chromatographic assay for the sulphoxide metabolite of 2'-deoxy-3'-thiacytidine in human urine. J. Chromatogr. B. Biomed. Sci. Appl., Amsterdam, v. 687, p. 457-461, 1996.

SOMMADOSSI, J.P.; SCHINAZI, R.F.; CHU, C.K.; XIE, M.Y. Comparison of citotoxicity of the (-)- and (+)enantiomer of 2'-deoxy-3'-thiacytidine in normal human bone marrow progenitor cells. Biochem. Pharmacol., New York, v. 44, p. 1921-1925, 1992.

Recebido para publicação em 02 de maio de 2002. 